\title{
Tracheo-oesophageal fistula and bilateral recurrent laryngeal nerve palsies after blunt chest trauma
}

\author{
REX DE L STANBRIDGE \\ From Harefield Hospital, Harefield, Middx
}

\begin{abstract}
A tracheo-oesophageal fistula resulting from blunt chest trauma is rare, with only 40 cases reported since $1936 .^{1-5}$ This is a report of the successful treatment of such a fistula, which was combined with a bilateral recurrent laryngeal nerve palsy and is the first such case. It is further unusual in that both presentation and repair occurred within 24 hours of injury.
\end{abstract}

\section{Case report}

A 23-year-old man fell out of his car and was hit by another passing car. He was unconscious from head injuries but was breathing satisfactorily. Surgical emphysema and bruising were present over his upper chest and neck. He vomited once and the vomit was bloodstained. A chest radiograph showed gross surgical emphysema, shallow bilateral pneumothoraces, and multiple right-sided rib fractures. Within an hour of admission his breathing became laboured. He was intubated and put on intermittent positive-pressure ventilation, and drainage tubes were inserted into each pleural cavity. Three hours later gross gastric dilatation was noted (fig 1); it was relieved by nasogastric suction. The arterial gases showed an $\mathrm{A}-\mathrm{a}$ shunt of $20 \%$ with a $\mathrm{PaO}_{2}$ of $106 \mathrm{mmHg}(14.1 \mathrm{kPa})$ and a $\mathrm{PaCO}_{2}$ of $48.7 \mathrm{mmHg}(6.5 \mathrm{kPa})$.

Rigid bronchoscopy showed a $5 \mathrm{~cm}$ longitudinal tear in the posterior wall of the trachea between 23 and $28 \mathrm{~cm}$ from the upper incisor teeth and ending $2 \mathrm{~cm}$ above the carina. Rigid oesophagoscopy showed, firstly, air bubbling up the oesophagoscope and, secondly, the balloon of the endotracheal tube at $24-25 \mathrm{~cm}$, exactly corresponding with the level of the tracheal tear. The endotracheal tube was replaced by a double-lumen endobronchial tube and the patient underwent an immediate right lateral thoracotomy through the fourth intercostal space, preserving the intercostal muscle bundle for a future pedicle graft.

The oesophagus was found to have two tears. One, a full-thickness anterior tear measuring $6 \mathrm{~cm}$ vertically, lay immediately alongside the tracheal tear. The second, a partial-thickness posterior tear measuring $7 \mathrm{~cm}$ vertically, was a muscular tear positioned immediately anterior to the vertebral column. The mucosa here was swollen but not ruptured.

The tracheal tear was of full thickness posteriorly and measured $5 \mathrm{~cm}$ vertically. There was extensive mediastinal emphysema and moderate inflammation between the trachea and oesophagus, the injury now being 20 hours

Address for reprint requests: Harefield Hospital, Harefield, Uxbridge, Middx UB9 6JH. old. The trachea was mobilised only on the right lateral and posterior aspects. The oesophageal tears were repaired with interrupted 3/o Ethibond, two layers being used for the full-thickness tear. The trachea was repaired with similar sutures and reinforced with an intercostal muscle pedicle graft. This muscle pedicle was placed behind the oesophagus and made to lie between the trachea and oesophagus, thereby separating the two organs (fig 2). The pleura was reconstituted and the chest closed with drainage.

After surgery, the patient was ventilated through a single-lumen endotracheal tube for four days, the cuff being positioned above the site of the tracheal repair; he was extubated at one week.

The surgical emphysema gradually settled and there was no evidence of a tracheal leak. A gastrografin swallow

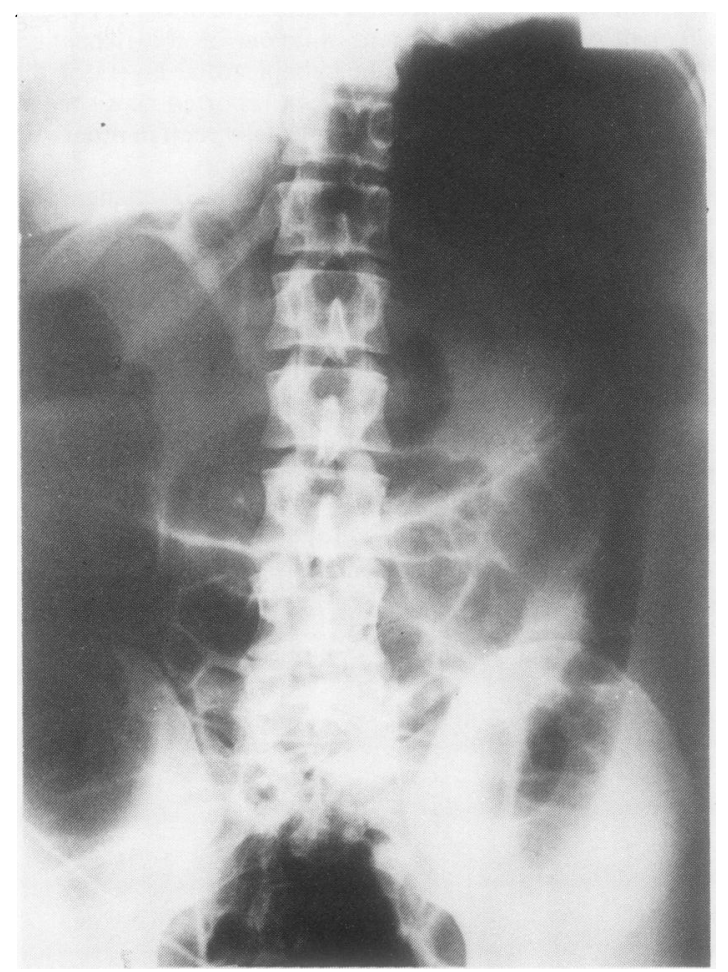

Fig 1 Supine abdominal radiograph showing gross gastric distension. 


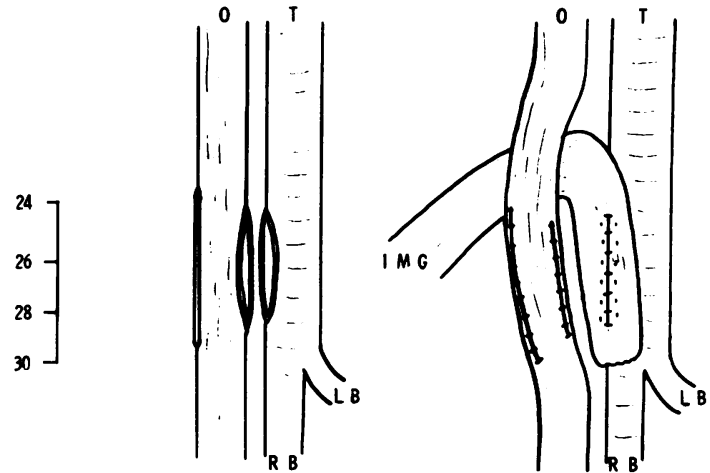

Fig 2 Diagrammatic illustration of (left) position of oesophageal and tracheal tears (full-thickness tears shown in double outline) and (right) method of repair. $O=$ oesophagus; $T=$ trachea; $R B=$ right bronchus; $L B=$ left bronchus; IMG = intercostal muscle graft. The scale on the left indicates the distance from the incisors in centimetres.

showed a satisfactory oesophageal lumen with no leakage. After extubation he had a soft hoarse voice, which remained ineffectual for several weeks. When he first attempted to drink, he immediately spluttered and coughed up some of the fluid. Indirect laryngoscopy showed a bilateral recurrent laryngeal nerve palsy, with both vocal cords immobile but partly abducted. He was able to take solid food more satisfactorily than fluids. He was discharged three weeks after the injury. Three months later he had regained his ability to swallow and recovered his voice and a further indirect laryngoscopy showed that both vocal cords were now moving normally.

\section{Discussion}

Rupture of the trachea and oesophagus in cases of blunt thoracic trauma is thought to be caused by compression of the manubrium against the vertebral column. ${ }^{13}$ This mechanism would adequately explain the three tears in "line astern" and the recurrent laryngeal nerve palsy in this patient. In $90 \%$ of cases the rupture of the trachea is immediate while that of the oesophagus is secondary to necrosis resulting from the crush; this results in a tracheooesophageal fistula occurring late, usually from three to five days after injury. ${ }^{1}$ In this case the anterior oesophageal wall was widely ruptured and the posterior wall injured in a manner likely to lead to a secondary rupture. The nature of these oesophageal tears indicates that a more severe compression than is usual with a traumatic tracheooesophageal fistula is likely to have been present in this case. This may also explain the bilateral recurrent laryngeal nerve palsy. As the left side of the trachea was not dissected at operation, it is unlikely that both nerves were damaged at the time of operation.

This case re-emphasises the following features of diagnosis and management of patients with a tracheooesophageal fistula:

\section{Diagnostic features}

1 Oesophageal injury indicated by bloodstained vomit

2 Oesophageal fistula indicated by gross gastric dilation during mechanical ventilation

3 Rupture of trachea indicated by gross surgical emphysema and a bilateral pneumothorax

\section{Steps in management}

1 Bronchoscopy and oesophagoscopy

2 Immediate repair using a graft, such as the intercostal muscle pedicle, to reinforce the suture lines and to separate the two injured organs, thereby preventing recurrent fistulae.

I would like to thank Miss MP Shepherd and Mr JW Jackson for their advice on the management of this case.

\section{References}

1 Chapman ND, Braun RA. The management of traumatic tracheo-oesophageal fistula caused by blunt chest trauma. Arch Surg 1970;100:681-4.

2 Valesky A, Schildberg FW, Heberer G. Diagnosis and treatment of tracheo-oesophageal fistulae. Prax Klin Pneumol 1979;33, suppl:459-61 (authors' translation).

${ }^{3}$ Layton TR. Tracheo-oseophageal fistula following nonpenetrating trauma. J Trauma 1980;20:802-5.

4 Lajam FE, Sakurai H, Mc Elhenney AJ. Tracheooesophageal fistula eight years after blunt trauma. $J$ Trauma 1979;19:123-5.

5 Guynes WA, Dickinson WE, Sutherland RD, Martinez HE. Tracheo-oesophageal fistula following blunt chest trauma. Tex Med 1979;75:52-3. 